\title{
Assessing the burden of Covid-19 in the slums of Bangalore city: Results of Rapid Community Survey
}

Ranganath Thimnahalli Sobagaiah ${ }^{1}$, Ramesh Masthi Nugehally Raju ${ }^{2}$, Lalitha Krishnappa ${ }^{3}$, Ambika Rangaiah $^{4}$, Girish Nagaraja Rao ${ }^{5}$, Riyaz Basha ${ }^{6}$, Sulekha Thimmaiah ${ }^{7}$, Renuka Venkatesh ${ }^{8}$, Seema Prakash ${ }^{9}$, Sathish Chandra Mallapanahalli Ranganath ${ }^{10}$, Kavita Srikanth Konapur ${ }^{11}$, Vidya Jeevan ${ }^{12}$, Shanthi Muddaiah ${ }^{13}$, Deepak Murthy Jagadish $^{14}$, Nitu Kumari ${ }^{15}$, Mysore Kalappa Sudarshan ${ }^{16}$

${ }^{1}$ Professor \& HOD, Department of Community Medicine, Bangalore Medical College \& Research Institute, Bangalore ; ${ }^{2}$ Professor \& HOD, Department of Community Medicine, Kempegowda Institute of Medical Sciences, Bangalore; ${ }^{3}$ Professor \& HOD, Department of Community Medicine, M S Ramaiah Medical College, Bangalore; ${ }^{4}$ Professor \& HOD, Department of Microbiology, Bangalore Medical College \& Research Institute, Bangalore; ${ }^{5}$ Professor, Centre for Public Health, National Institute of Mental Health and Neurosciences, Bangalore; ${ }^{6}$ Professor, Department of Community Medicine, Sri Atal Bihari Vajpayee Medical College \& Research Institute, Bangalore; ${ }^{7}$ Professor, Department of Community Medicine, St. Johns Medical College, Bangalore; ${ }^{8}$ Professor, Department of Community Medicine, Sapthagiri Institute of Medical Sciences, Bangalore; ${ }^{9}$ Associate Professor, Department of Community Medicine, ESI Medical College and Research Institute, Bangalore; ${ }^{10}$ Associate Professor, Department of Community Medicine, BGS Institute of Medical Sciences, Bangalore; ${ }^{11}$ Assistant Professor, Department of Community Medicine, Vydehi Institute of Medical Sciences, Bangalore; ${ }^{12}$ Associate Professor, Department of Community Medicine, Raja Rajeshwari Medical College, Bangalore; ${ }^{13}$ Assistant Professor, Department of Community Medicine, Dr B R Ambedkar Medical College. Bangalore, ${ }^{14}$ Senior Residents, Bangalore Medical College and Research Centre, Bangalore, ${ }^{15}$ Senior Resident, Bangalore Medical College and Research Centre, Bangalore; ${ }^{16}$ Chairman, Technical Advisory Committee, Government of Karnataka, Bangalore-560070, Karnataka.

\begin{tabular}{|c|c|c|c|c|c|c|c|}
\hline Abstract & Introduction & Methodology & Results & Conclusion & References & Citation & Tables/ Figures \\
\hline
\end{tabular}

\section{Corresponding Author}

Dr Ramesh Masthi, Professor \& HOD of Community Medicine, Kempegowda Institute of Medical Sciences, Bangalore -560070, Karnataka

E Mail ID: ramesh.masthi@gmail.com

\section{Citation}

Sobagaiah RT, Masthi RNR, Krishnappa L, Rangaiah A, Rao GN, Basha R, Thimmaiah S, Venkatesh R, Prakash S, Ranganath SCM, Konapur KS, Jeevan V, Muddaiah S, Jagadish DM, Kumari N, Sudarshan MK. Assessing the burden of Covid-19 in the slums of Bangalore city: Results of Rapid Community Survey. Indian J Comm Health. 2021;33(3):475-479. https://doi.org/10.47203/IJCH.2021.v33i03.012

Source of Funding: Rajiv Gandhi University of Health Sciences, Karnataka, India Conflict of Interest: None declared

\section{Article Cycle}

Received: 17/07/2021; Revision: 28/09/2021; Accepted: 05/09/2021; Published: 30/09/2021

This work is licensed under a Creative Commons Attribution 4.0 International License.

\section{Abstract}

Background: Karnataka, more so Bangalore, reported an increase in number of COVID-19 cases in early April 2021. Objective: To assess the burden of COVID-19 in the slums of Bengaluru city. Materials and Methods: A cross-sectional multi centre community-based study was done in the 2nd and 3rd week of April 2021 in 24 different slums in Bangalore city. WHO cluster random sampling technique was followed. Swabs for RTPCR test and $4 \mathrm{ml}$ of venous blood was collected from 728 subjects more than 18 years of age. Results: A total of 51 (7\%) subjects were positive for COVID-19 through RT-PCR. Majority 33 (56.9\%) were in the age group of 18-44 years. $148(20.3 \%)$ subjects were sero-positive on blood examination and 18-44 years was the (59.4\%) preponderant age group. Overall seropositivity was $20.3 \%(95 \% \mathrm{Cl} ; 17.4-23.2)$ and RT-PCR positivity is $7 \%$ $(95 \% \mathrm{Cl} ; 5.2-8.8 \%)$ among the subjects surveyed. In the inner core area of Bangalore, seropositivity was $24.2 \%(95 \% \mathrm{Cl} ; 21.0-$ 27.3 ) and RT-PCR positivity was $8 \%(95 \% \mathrm{Cl} ; 6.1-9.9)$. Two doses of COVID-19 vaccine were taken only by $1.55 \%$ subjects during the study period. Conclusion: The study showed that one in 5 subjects were sero-positive to SARS-CoV-2 and one in 15 individuals had active COVID-19 infection.

\section{Keywords}

Urban slums; COVID-19; Serosurvey 


\section{Introduction}

Severe acute respiratory syndrome coronavirus 2 (SARSCoV-2) is responsible for pandemic of coronavirus disease 2019 (COVID-19).(1) The worldwide transmission of COVID-19 is spreading like wildfire in 2021, affecting almost all countries in the world.

India had reported the second highest number of confirmed cases globally.(2) The large size, geographical diversity, and population heterogeneity, makes it difficult to understand the extent of transmission of SARS-CoV-2 using case-based surveillance data alone.(3) The estimation of COVID-19 burden based on medically attended case numbers is suboptimal.(4) The seroprevalence of SARS-CoV-2 antibodies is important to understand the total infections, including mild and asymptomatic cases.(5) ICMR has conducted three national serosurvey across 21 States, that included high and low prevalence infection districts.(6) COVID-19 serosurveys have been conducted in many states, districts, sub-districts and seropositivity ranged from $0.73 \%$ to $21.5 \% .(7,8,9)$ Furthermore, Indian urban slum population represent challenging conditions for COVID-19 control, with some of the world's highest population densities and contact rates.(3) Karnataka, more so Bangalore started to report an increase in number of cases in early April,2021. Households in the slums live in areas that are conducive to transmission of COVID-19.(5) However, many experts had expressed surprise about fewer reports of COVID-19 in this population.(2)

\section{Aims \& Objectives}

To assess the burden of COVID-19 in the slums of Bengaluru city

\section{Material \& Methods}

The staff from the department of community medicine from 11 medical colleges in Bangalore city and Department of Epidemiology, Center for public health, NIMHANS formed the survey team. The department of Microbiology, Bangalore Medical College \& Research Institute (BMCRI), Bangalore was the nodal centre for IgG blood sample analysis. Principal investigators were identified from the respective colleges. A total of 24 slums attached to the Urban Health Training Centres of the medical colleges in Bangalore was the study area (Figure 1).

The residents of slums in the urban field practice area of respective colleges, more than 18-year of age and nonvaccinated were the study subjects. The selection of medical colleges, Principal Investigators, development of survey proforma, were all completed in first week of April 2021 ; followed by house-to-house survey in 2nd and 3rd week of April 2021. This was a cross-sectional multi centre community-based study. A total of 720 subjects was determined keeping the feasibility and constrains (impending second wave(2)) in conducting the study. 60 subjects per medical college, 2 slums UPHC/UHTC field practice area and 30 subjects per slum were surveyed. WHO EPI 30 Cluster sampling technique was followed for selection of subjects in each slum. Selection of the street, household and direction of survey was random. Subsequently households were surveyed in a continuous series until the required sample size was met.(10) Inclusion criteria: The subject should be resident in the area, must not have previously participated in a similar survey and should not have received COVID-19 vaccine. Data collection: After taking signed informed consent from the subjects, information was collected in Epicollect5 application and details about socio-demographic profile, household details, location co-ordinates, any case of COVID-19 in the household, history of COVID -19 vaccination of other members in the family, sample registration form (SRF) ID and blood sample number were collected.(11) In each slum, subjects over 18 years of age, those mostly engaged in outdoor activities like drivers, house maids, cooks, laborers, workmen, students, street vendors, salespersons, and persons over 60 years of age, etc were included. The ICMR COVID-19 protocol of swab collection was followed for RTPCR test along with $4 \mathrm{~mL}$ of venous blood for IgG estimation was collected from the same subject. The Swab collector/ASHA/Staff nurse of the UPHC were utilized for the survey, swab collection and Laboratory technician/Staff nurse from UPHC/ medical college were utilized for blood collection. The RT PCR swab was sent as part of routine surveillance for COVID-19 disease by the UPHC staff and results of RT-PCR were extracted from Bhruhat Bangalore Mahanagara Palike (BBMP) war room data. The blood samples were centrifuged, and serum was transported for antibody testing. Samples were tested for Anti- SARS-CoV-2 IgG using COVID Kavach (Zydus Cadila) according to kit instructions. Results were interpreted as Positive or Negative in relation to the calculated cut-off value.(12) The testing kit is approved by ICMR with sensitivity of $92.1 \%$ and specificity of $97.7 \%$, results of test were collected from department of microbiology, BMCRI. Ethical Statement: Expedited Institutional Ethics Committee (IEC) approvals were taken from every institution participating in this survey. The permission letters were taken from Rajiv Gandhi University of Health Sciences (RGUHS), Commissioner \& Chief Health Officer of BBMP, and cooperation of UPHC staff for the study was ensured. Informed consent form in the local language was signed by each subject and confidentiality of the subjects was always maintained. Data management: The different data from Epicollect5 were merged to Microsoft Excel and data was analyse using IBM SPSS (v 20) software.(13) Results were expressed in proportions, median and Inter quartile range and presented in the form of tables. Poisson log linear regression was used to calculate prevalence ratio and adjusted prevalence ratio for sero positivity and RT-PCR positivity. 


\section{Results}

Sociodemographic Profile: A total of 728 households (over and above the 720 planned) were surveyed and 1562 individuals were interviewed. Among 1562 individuals, 812 (52\%) were males with median age of 34 (IQR 25-46) years and 750 (48\%) were females with median age of 34 (IQR 26-47) years. Majority (61.1\%) subjects belonged to age group of 18-44 years. About 133 (8.5\%) subjects were elderly i.e., more than 60 years of age.

About 332 (21.2\%) subjects were laborers by occupation, 70 (4.5\%) were drivers and 141 (9\%) were unemployed. Majority 299 (39.9\%) females were home makers. About 496 (31.8\%) had completed high school and 406 (26\%) were illiterates. Majority 1150 (73.6\%) had earning less than Rs.10,000 a month.

Sero-Positivity: Among the 728 surveyed subjects for RTPCR positivity and IgG, Overall seropositivity was $20.3 \%$ (95\% $\mathrm{Cl}$; $17.4-23.2)$ and RT-PCR positivity was $7 \%(95 \% \mathrm{Cl}$; 5.2-8.8). Seropositivity and RT-PCR positivity was more in the inner core area of Bangalore city with $24.2 \%(95 \% \mathrm{Cl}$; 21.0-27.3) and $8 \%(95 \% \mathrm{Cl} ; 6.1-9.9)$ when compared to outer core which was $12.5 \%(95 \% \mathrm{Cl} ; 10.1-14.9)$ and $3.8 \%$ $(95 \% \mathrm{Cl} ; 2.5-5.1)$ of the surveyed area (Table 1$).(14)$ A total of 51 (7\%) subjects were positive for COVID-19 by RT-PCR test. 33 (56.9\%) were in the age group of $18-44$ years, the mean age among males was $39.3(13.4)$ years and females was 40.1 (14.7) years. 28 (55\%) were males, 18 (35.3\%) were illiterates, 7 (13.7\%) were labourers, 9 (17.6\%) were unemployed and 12 (23.5\%) had other occupation.

148 (20.3\%) subjects were sero-positive for IgG. 88 (59.4\%) seropositive subjects belonged to age group of 18 44 years, the mean age among males was 41.45 (13.2) years and females was $40.58(13.8)$ years. 90 (60.1\%) were females, 52 (35.1\%) had completed their high school, 28 (18.9\%) were labourers, 8 (5.4\%) were street vendors, 26 (17.7\%) were home makers and 109 (73.6\%) earns less than Rs.10,000 a month.

It was observed that RT-PCR positive and IgG positive was 7 (09\%), RT-PCR positive and IgG negative was 44 (6.1\%), RT-PCR negative and IgG positive was 141 (19.3\%) and RTPCR negative and IgG negative was 536 (73.7\%) among the study participants as described in (Table 2).

The sero-positivity was $1.57(1.1-2.24)$ times more prevalent among the age group of 45-60 years and 1.12 (062-2.01) times more among the age group of $>60$ years $(p<0.05)$. Females were $1.53(1.1-2.14)$ times more likely to have sero-positive compared to males $(p<0.05)$. Those who had COVID-19 like symptoms were 0.83 (0.42-1.65) times less sero-positive when compared to those who had no symptoms. People having contact with COVID-19 case were $1.70(0.78-3.68)$ times more likely to become seropositive and those having a case in the household were 1.38 (0.73-4.35) times more sero-positive (Table 3).
The RT-PCR positivity was $1.34(0.68-2.63)$ times more prevalent among those with co-morbidity. In presence of COVID-19 related symptoms, the RT-PCR positivity was 3.11 (1.55-6.25) times more prevalent and individuals who were primary contact of COVID-19 case were 1.70 (0.783.68) times more prevalent for RT PCR positivity.

Out of 1562, 834 individuals were not part of the serosurvey, and it was observed that only 39(4.67\%) subjects were vaccinated with either one/two dose of vaccine, 26(3.1\%) had taken one dose of the vaccine and $13(1.55 \%)$ were vaccinated fully with two doses.

\section{Discussion}

This is the first study in Karnataka, that estimates the proportions of people living in urban slums with SARSCoV-2 Infection (IgG antibody positive) and currently have an active disease (RT-PCR positive). In view of the recent surge in COVID-19 cases in Bangalore city and in continuation with the recommendations from Technical Advisory Committee, Government of Karnataka this Survey was conducted in the slums of Bangalore city. The ICMR has carried out three nationwide serology surveys and estimated level of IgG antibody among the population in the country ranged from $0.73 \%$ in May June 2020, 7\% in August-September 2020 survey and $21.5 \%$ in December 20 to January 21 survey. The survey was spanned in 70 districts across 21 States, that included high and low prevalence infection districts and covered 28,000 people. $(6,7,8)$ ICMR studies have observed that significant proportion of the population is still vulnerable like the observations of present study, though the population covered was small. The distribution of COVID19 among urban slums has been non-uniform, positivity was more in the inner core area and may be attributed to the dense population.

Adjusted seroprevalence across Karnataka in rural and urban was $46.7 \%$, higher than the present study.(15) Similarly, $16.8 \%$ IgG positivity and active infection fraction was $12.6 \%$, lower than the observation of the present study.(16) However, another study in of Bangalore city in December 2020 had observed a seropositivity of more than $50 \% .(17)$

Elderly, people with history of contact with COVID-19 and those with comorbidities had a higher prevalence of COVID-19 this is in concordance with serosurveys across the country. $(6,7,8,15,16,17,18)$ Complete vaccination was found only in less than $2 \%$ and there is an urgent need to scale up vaccination in the urban slums of Bangalore city. RT-PCR negative and IgG negative was observed in three fourth of the subjects. $9 \%$ of the subjects in this study showed both viral RNA and IgG antibodies, to include genomic sequencing and require further examination regarding this.

Slum dwellers may have developed antibody and not reflected in the antibody titres. Cell mediated immunity is probably playing a role and further research may throw 
light in accordance with a study where anti-SARS-CoV-2 spike (S) antibodies decline rapidly over the months. $(19,20)$ Regular sero-surveys at national, state and even district levels to estimate sero-positivity is needed. Many countries have opted to perform sero-tests to estimate immunity levels regularly.(15)

\section{Conclusion}

The study indicates that nearly one in 5 subjects was seropositive to SARS-CoV-2 and one in 15 individuals had active COVID-19 with infection-to-case ratio of $3: 1$ in urban slums of Bangalore during April 2021. Seropositivity and RT-PCR positivity is more in the inner core area of Bangalore city when compared to outer core. Overall COVID-19 complete vaccination was observed in only $1.55 \%$ subjects.

\section{Recommendation}

Exclusive vaccination sessions for all the eligible beneficiaries in urban slums and continued expansion of testing and application of interventions to control the further transmission is recommended.

\section{Limitation of the study}

This survey was conducted during the start of second wave in Karnataka, hence seropositivity and RT-PCR positivity may not reflect the actual scenario. WHO cluster sampling technique was difficult to be followed in some of the surveyed sites due to constraints in the field. The sample size is too small for generalization and a bigger study with large population covered is required. The card test has its limitation of sensitivity and specificity.

\section{Relevance of the study}

Although the seroprevalence among adults increased with age, surveyed area and risk category, a large proportion of the population remains susceptible to SARS-CoV- 2 .

\section{Authors Contribution}

conceived and designed the study; TSR, NRRM, MKS developed the data extraction tool; NRM, MKS trained data collectors and were involved in data collection; NRRM,NK,TSR analysed the data; NRM, DMHJ interpreted and visualized the data; NRM, DMHJ, TSR prepared the first draft; NRRM all authors critically reviewed the manuscript for important intellectual content and approved the final draft for submission

\section{Acknowledgement}

We would like to thank Honourable Vice Chancellor Dr S Sacchidanand, Dr Ramakrishna Reddy, Registrar of RGUHS and Dr Dayanand, Deputy Registrar of RGUHS for all the support for this study. We are thankful to Sri Gaurav Gupta, BBMP commissioner, Dr Vijeyandra, Chief Health Officer, Medical officers-UPHC, Lab Technicians, and ASHA workers for their support and cooperation. We are thankful to the Dean \& Principals of 11 Medical colleges, HODs of community medicine of these colleges, survey team members from the medical colleges and
Department of Epidemiology, Centre for Public Health, NIMHANS without their support, the survey would not have been possible. We thank the staff of Department of Microbiology, BMCRI for assessing the survey samples for seropositivity in a noticeably short period. We would like to thank the Karnataka Association of Community Health (KACH) for its support in the study. We like to thank all the Participants who volunteered to be part of this study but for whom the study would not have been possible.

\section{References}

1. WHO. A coordinated global research roadmap: 2019 novel coronavirus; March 2021. Geneva: World Health Organization, 2021

2. COVID-19 MEDIA BULLETIN [press release] 2021 . Available from https://covid19.karnataka.gov.in ( cited June2nd,2021).

3. Ministry of Health and Family Welfare G. COVID-19 INDIA. Available from: https://www.mohfw.gov.in/(cited June 5th, 2021).

4. Government of India. COVID-19 dashboard. May 30, 2021. https://www.mygov.in/covid-19 (cited May 30, 2021).

5. Indian Council of Medical Research, New Delhi [Internet]. [cited 2021 Jun 29]. Available from: https://www.icmr.gov.in(cited June 5th 2021).

6. Third nationwide sero-survey shows that large population still vulnerable to COVID-19, says ICMR. available from https://www.firstpost.com/india/third-nationwide-sero-survey-showsthat-large-population-still-vulnerable-to-covid-19-says-icmr9272271.html . cited on 28.05.21 (cited June 5th , 2021).

7. SARS-CoV-2 antibody seroprevalence in India, August-September 2020 findings from the second nationwide household serosurvey. Available from https://www.thelancet.com/journals/langlo/article/PIIS2214109X(20)30544-1/fulltext\#seccestitle 150 (Cited January 20th , 2021).

8. Murhekar MV, Bhatnagar T, Selvaraju S, Rade K, Saravanakumar V, Vivian Thangaraj JW, et .al. Prevalence of SARS-CoV-2 infection in India: Findings from the national serosurvey, May-June 2020. Indian J Med Res 2020; 152:48-60

9. QGIS Cloud - Deepak [Internet]. Available from https://qgiscloud.com/chethanhn/Deepak/?bl=\&l=colleges\%2CSurvey \%20Site\%2CLocation\%2CInner\%20Core\%2CCartoDb\%20Positron\&t=D eepak\&e=8611257\%2C1441877\%2C8660176\%2C1464617 [cited Jun 29 2021].

10. MLM_module7.pdf [Internet]. Available from: https://www.who.int/immunization/documents/MLM_module7.pdf (cited June 5th , 2021).

11. Free and easy-to-use mobile data-gathering platform. [Internet]. Available from: https://five.epicollect.net/ [cited 2021 Jun 29].

12. ELISA_CLIA_Kits_List_03112020_v1.pdf [Internet]. Available from: https://www.icmr.gov.in/pdf/covid/kits/ELISA_CLIA_Kits_List_031120 20_v1.pdf (cited Jun 29 2021).

13. SPSS Statistics 20 Available for Download [Internet]. 2020 Available from: $\quad$ https://www.ibm.com/support/pages/spss-statistics-20available-download (cited 2021 Jun 29).

14. Zoning_Regulations_RMP2015f (1).pdf [Internet]. Available from https://bbmp.gov.in/PDF/townplanning/Zoning Regulations RMP201 5f\%20(1).pdf (cited Jun 22 2021).

15. Prevalence of Covid-19 in Rural Versus Urban Areas in a Low-Income Country: Findings from a State-Wide Study in Karnataka.Available from https://www.medrxiv.org/ content/10.1101/2020.11.02.20224782v1 full (Cited May 28th,2021).

16. GiridharaR Babu, Rajesh Sundaresan, Siva Athreya, Jawaid Akhtar, Pankaj Kumar Pandey, Parimala S Maroor, et al. The burden of active infection and anti-SARS-CoV-2 IgG antibodies in the general population: Results from a statewide survey in Karnataka, India. Int J Infect Dis. 2021 May 21; 108:27-36. doi: 10.1016/j.ijid.2021.05.043.

17. N R Ramesh Masthi, Divya Bharathi G, Pruthvi SG, Munish Mudgal, Shivakumar S, T V Sanjay, Giriyanna Gowda; A community based serosurvey for SARS-CoV2 among population in an assembly constituency of urban Bangalore, Karnataka; RGUHS National Journal of Public Health 2021; 6 (2), 19-22.

18. Technical-Paper-COVID-19-ICMR-Sero-SurveillanceStudy.docx.pdf.Available from https://arogyakeralam.gov.in/wpcontent/uploads/2020/03/Technical-Paper-COVID-19-ICMR-SeroSurveillance-Study.docx.pdf(cited june28th 2021). 
INDIAN JOURNAL OF COMMUNITY HEALTH / VOL 33 / ISSUE NO 03 / JUL-SEP 2021

19. Radbruch A, Chang H-D. A long-term perspective on immunity to COVID. Nature. 2021 Jun 14; d41586-021-01557-z.

20. Deckert A, Anders S, de Allegri M, Nguyen HT, Souares A, McMahon S, et al. Effectiveness and cost-effectiveness of four different strategies for
[COVID-19 burden in slums...] | Ranganath TS et al SARS-CoV-2 surveillance in the general population (CoV-Surv Study): a structured summary of a study protocol for a cluster-randomised, twofactorial controlled trial. Trials. 2021 Dec;22(1):39.

\section{Tables}

\section{TABLE 1 RT-PCR POSITIVITY AND IGG POSITIVITY IN THE SURVYED AREA}

\begin{tabular}{|c|c|c|c|c|}
\hline \multicolumn{2}{|c|}{ Name of the survey area } & Total tested & RT-PCR positive & IgG positive \\
\hline \multirow[t]{8}{*}{ Inner core area } & Yarabnagar, Jayanagar & 60 & $6(10.0)$ & $25(41.0)$ \\
\hline & Mariyappanapalya & 60 & $15(25.0)$ & $22(36.7)$ \\
\hline & H Siddaiah Road & 60 & $2(3.3)$ & $15(25.0)$ \\
\hline & Mathikere, Nethaji circle & 60 & $1(1.7)$ & $15(25.0)$ \\
\hline & DJ halli, KG halli & 60 & $1(1.7)$ & $12(20.0)$ \\
\hline & Thavarekere, Sonnenahalli & 67 & $9(3.4)$ & $10(14.9)$ \\
\hline & Austin town & 61 & $3(4.9)$ & $9(14.8)$ \\
\hline & Kengeri, Uttarahalli & 60 & $2(3.3)$ & $8(13.3)$ \\
\hline \multirow[t]{4}{*}{ Outer core area } & Bangarappa Nagara & 60 & - & $11(18.3)$ \\
\hline & Mallasandra & 60 & $4(6.7)$ & $9(15.0)$ \\
\hline & Siddapura & 60 & $5(8.3)$ & $6(10.0)$ \\
\hline & K Narayanapura & 60 & $3(5.0)$ & $4(6.7)$ \\
\hline
\end{tabular}

TABLE 2 CATEGORISATION OF SUBJECTS BASED ON THE RESULTS OF THE TESTING OF RT-PCR \& COVID -19

\begin{tabular}{|c|c|c|c|c|}
\hline \multirow[t]{2}{*}{ RT-PCR Test } & \multicolumn{3}{|c|}{ Covid -19 Antibody } & \\
\hline & \multicolumn{2}{|r|}{ Positive } & Negative & Total \\
\hline Positive & CAT -I & 07 (04.8\%) & CAT -II $44(07.5 \%)$ & $51(07.1 \%)$ \\
\hline Negative & CAT-III & $141(95.2 \%)$ & CAT-IV $536(92.5 \%)$ & $677(92.9 \%)$ \\
\hline Total & & $148(100.0 \%)$ & $580(100.0 \%)$ & $728(100.0 \%)$ \\
\hline
\end{tabular}

*Figures in parenthesis indicate percentage.; Note: Category I: RT-PCR positive \& IgG positive; denotes present and past infection = 7 (09\%); Category II: RT-PCR positive and IgG negative; denotes Present infection = 44 (6.1\%); Category III: RT-PCR negative and IgG positive; denotes past infection =141 (19.3\%); Category IV: $R T$-PCR negative and Ig G negative; denotes Not infected = 536 (73.7\%)

TABLE 3 PREVALENCE RATIO (PR) AND ADJUSTED PREVALENCE RATIO (APR) OF SERO-POSITIVITY (N=728)

\begin{tabular}{|c|c|c|c|c|c|}
\hline & Characteristics & $\begin{array}{r}\text { Surveyed } \\
\text { subjects [N (\%)] }\end{array}$ & $\begin{array}{r}\text { Seropositive } \\
\text { participants [N (\%)] }\end{array}$ & PR (95\% CI) & $\operatorname{aPR}(95 \% \mathrm{Cl})$ \\
\hline & Overall & $728(100.0)$ & $148(20.3)$ & & \\
\hline \multirow[t]{3}{*}{ Age } & $18-45$ & $496(100.0)$ & $88(17.7)$ & 1 & 1 \\
\hline & $45-60$ & $166(100.0)$ & $47(28.3)$ & $1.59(1.12-2.27)^{*}$ & $1.57(1.1-2.24)^{*}$ \\
\hline & $>60$ & $66(100.0)$ & $13(19.7)$ & $1.11(0.62-1.98)^{*}$ & $1.12(0.62-2.01)^{*}$ \\
\hline \multirow[t]{2}{*}{ Sex } & Male & $363(100.0)$ & $58(16.0)$ & 1 & 1 \\
\hline & Female & $365(100.0))$ & $90(24.7)$ & $1.54(1.1-2.14)^{*}$ & $1.53(1.1-2.14)^{*}$ \\
\hline \multirow{2}{*}{$\begin{array}{l}\text { H/o COVID-19 related } \\
\text { symptoms }\end{array}$} & No & $677(100.0)$ & $139(20.5)$ & 1 & 1 \\
\hline & Yes & $51(100.0)$ & $9(17.6)$ & $0.86(0.43-1.68)$ & $0.83(0.42-1.65)$ \\
\hline \multirow{2}{*}{$\begin{array}{l}\text { H/o contact with COVID-19 } \\
\text { case }\end{array}$} & No & $702(100.0)$ & $139(19.8)$ & 1 & 1 \\
\hline & Yes & $26(100.0)$ & $9(34.6)$ & $1.74(0.89-3.43)$ & $1.70(0.78-3.68)$ \\
\hline \multirow{2}{*}{$\begin{array}{l}\text { Present COVID-19 RT-PCR } \\
\text { result }\end{array}$} & Negative & $677(100.0)$ & 141 (20.9) & 1 & 1 \\
\hline & Positive & $51(100.0)$ & 7 (13.7) & $0.65(0.3-1.4)$ & $0.67(0.31-1.45)$ \\
\hline
\end{tabular}

\section{Figures}

FIGURE 1 QGIS LOCATIONS OF THE SURVEYED AREA HTTPS://QGISCLOUD.COM/CHETHANHN/DEEPAK/(9)

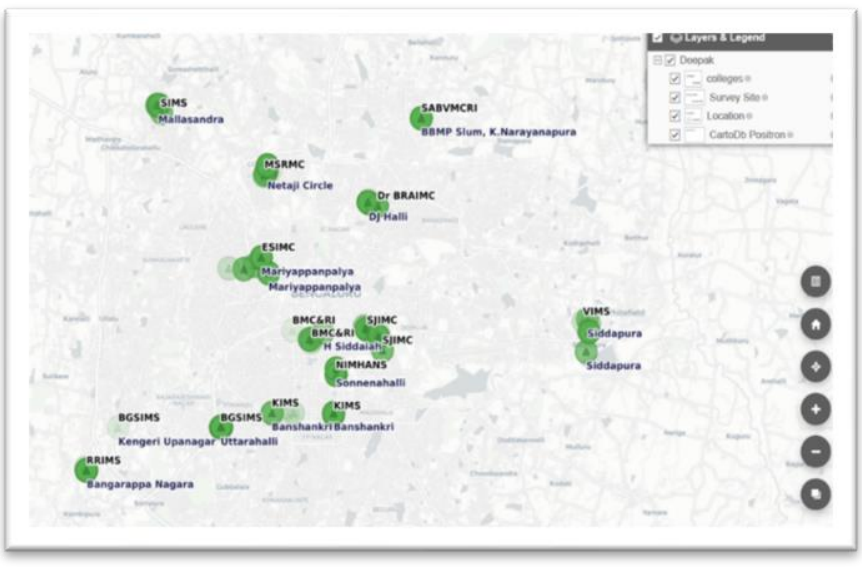

